\title{
Postmodernisme: doelgerig of vrolike fuif? 'n Polisieroman en 'n moorddroom
}

"Daardie lewe is net nog 'n woord..." (Miles, 1991:16)

\begin{abstract}
The incredulity towards metanarratives in the postmodernist era holds serious implications for historiography. Two "historiographic metafictional novels" (Hutcheon's term), one Flemish and one Afrikaans, are discussed in this article. There is a significant difference in the way these two lexts react to ontological doubt. On the one hand there is a celebration of the loss of metanarratives in Het beleg van Laken (Walter van den Broeck). On the other hand this loss is used in a very serious way to undermine existing metanarratives in Kronick uit die doofpot (John Miles). The joyous humour and celebration in Het heleg van Laken is absem in Kroniek uit die doofpot. It is concluded that some historiographic metafiction frivolously celebrates decentring and the incredulity towards metanarratives. In other historiographic metafiction ontological dowbt manifests without humour or celebration and serves to undermine metanarratives. It might be true that the celebration belongs to a late capitalist Western culture whereas it is unsuilable for a developing country.
\end{abstract}

\section{Inleiding}

Die basis vir ' $n$ hele reeks diskoerse word in die 'postmodernistiese era' geherwaardeer. Hierdie herwaarderings kom almal tot dieselfde konklusie: hoe harder enige diskoers soek na fundering, hoe meer word bevind dat daar geen fundering vir hierdie diskoers bestaan nie - en ook nie vir enige ander diskoers nie. In die eerste deel van hierdie artikel word, na aanleiding van veral Lyotard (1984), 'n agtergrond tot ons tyd se verlies aan funderings (meesterverhale) ondersoek.

Tweedens word gewys op die implikasies hiervan vir historiografie, na aanleiding van die problematisering van geskiedenis in resente fiksie. Ek maak gebruik van Hutcheon (1989) se term historiografiese metafiksie. Opvallende verskille in die 
wyse waarop daar in twee romans, een Vlaams (Walter van den Broeck se Het beleg van Laken - 1985) $)^{\mathrm{l}}$ en een Afrikaans (John Miles se Kroniek uit die doof$p o t-1991)^{2}$, op ontologiese onsekerheid in historiografie gereageer word, word dan bespreek. Daar word gewys op 'n vrolike viering van die verlies aan meesternarratiewe in Het beleg van Laken. Andersyds word aangedui hoedat hierdie verlies met erns, doelgerig aangewend word om bestaande metanarratiewe te ondergrawe. Die speelsheid en humor van Het beleg van Laken ontbreek in Kroniek uit die doofpot. Het beleg van Laken se subtitel "een moorddroom" sou onvanpas wees vir die polisieroman. In Kroniek uit die doofpot is daar dodelike erns; nie 'n moorddroom nie, maar moord.

\section{Ontologiese twyfel}

Sentraal in Lyotard (1984) se bepreking van die 'postmoderne kondisie', staan die dood van sentrums en die wantroue ten opsigte van enige metanarratiewe.

Geen organiserende raamwerke, meesternarratiewe, wat tevore as 'natuurlik' en daarom as legitiem aanvaar is, word meer as sodanig aanvaar nie. Elk van hierdie 'raamwerke' het sekere sentrums veronderstel en bevoorreg. Hierdie raamwerke is/was bloot tydelike fiksies wat nuttig is/was vir die artikulasie van, nie universele nie, maar baie spesifieke belange (dié van die sentrum).

Legitimisering is onmoontlik in 'n wêreld waar slegs narratiewe en metanarratiewe bestaan. Onder metanarratief (métarécits), of meesterverhaal, verstaan Lyotard alle beskouings van 'n samelewing; die netwerk van vooronderstellings, religieus-polities-filosofiese oortuigings wat die samelewing bepaal, maar geen inherente regverdiging het nie. Alle konstrukte van die mens deur die eeue, hetsy polities of religieus, was bloot metanarratiewe wat hulself nie kan regverdig nie. Dit is aan hierdie metanarratiewe wat die postmodernistiese literatuur, volgens Lyotard se opvatting, uitdrukking gee, deur die afwesigheid van enige legitimisering te tematiseer. 'n Postmodernistiese teks is dus deurtrek van ontologiese twyfel.

Al wat naderhand sal oorbly, is petites histoires - klein geskiedenissies - wat altyd voorlopige regverdiging aan 'n groep se optrede sal verskaf, nooit ontologies-verankerde regverdiging nie. Hierdie 'klein fiksies' (petites histoires) sal altyd uitdrukking wees van eie fiksionaliteit en die ontoereikendheid van taal om iets vas te lê.

1 Het beleg van laken (Vandenbrocck - 1985). Voortaan word verwysings na hicrdic roman soos volg aangedui: Laken bladsynommer.

2 Kroniek uit die doofpot (Miles - 1991). Voortaan word verwysings na hicrdic roman soos volg aangedui: Kromek:bladsynommcr 
Ontologiese twyfel word dikwels verwelkom ${ }^{3}$ en dit hoef nie te lei tot swartgalligheid nie ${ }^{4}$. Daar is ook nie noodwendig 'n nostalgiese verlange na die sentrums van die verlede nie maar inderdaad 'n viering van die ontologiese twyfel. Soos ek ook verder in hierdie artikel gaan aantoon, kan die verlies aan sentrums ook strategies benut word.

\section{Historiografiese metafiksie}

Ontologiese twyfel word dikwels beskou as die belangrikste kenmerk van postmodemistiese fiksie. ${ }^{5}$ Hutcheon (1989) gebruik die term historiografiese melafiksie vir tekste waarin ontologiese twyfel vooropstaan en die geskiedenis as gevolg daarvan geproblematiseer word. Hierdie problematisering geskied deurdat die 'rame' rondom fiksie en geskiedenis ondergrawe word:

Fiction and history are narratives distinguished by their frames, frames which historiographic metafiction first establishes and then crosses, positing both the generic contracts of fiction and of history (Hutcheon, 1988: 109).

\section{Geskiedenis in Het beleg van Laken en Kroniek uit die doofpot}

In albei tekste is skrywers selfbewustelik besig om 'geskiedenis' te skryf. In albei gevalle is die skrywers besig om hulle verhale te grond op sekere tekste tot hulle beskikking; in die geval van Kroniek uit die doofpor word die dokumentasie oor Tumelo John se lewe gebruik en in die geval van Het beleg van Laken die twee besoekers (Mallants en Loracq) se weergawes van die geskiedenis van die koningshuis asook tekste wat vroeër, op skool, deur die skrywer (Van den Broeck) geskryf is. 6

3 Mchale (1987:217-333) verwelkom ontologicse twyfel in 'n afdeling met dic titcl: "How I learned to stop worrying and love postmodernism". Vir Hutchcon $(1989: \mathrm{x})$ verskaf dic paradoksc van postmodernisticse tckste plesicr. Dic paradoksalc aard moct nic tot mocdcloosheid lei nic, maar moct gevicr word (1988 73).

4 Vergelyk byvoorbecld in hierdic verband die gewildheid van 'n werk soos Peter Sloterdijk se Kritick van de cynische rede (1992)

Dit is waar dat skcptisisme en vihilisme nog altyd in dic 'Wcsterse tradisic' aanwesig was Vrocër was dit egter marginaal binne die groter diskocrs, terwyl dit tans dominerend op byna alle terreine van dic kultuur is

5 Let veral op dic werk van McHale (1987) wat ontologiese twyfel as dominant (Jacobson sc term) van postmodemisticse tekste beskou - in tecnstelling met epistemologic as dominant van dic Modernisme

6 Vitvocrig verduidelik deur Bousset (1990:77). 
Vir Jenkins (1991) word geskiedskrywing bepaal deur 'n epistemologie, 'n metodologie en 'n ideologie. Die epistemologie wys, volgens Jenkins (1991:19), daarop dat die verlede nooit werklik geken kan word nie aangesien die gaping tussen die verlede en geskiedskrywing 'n ontologiese gaping is, onoorbrugbaar deur epistemologiese pogings. Epistemologiese probleme sluit onder meer ook in dat die studieveld vir die geskiedskrywer eenvoudig onbeperk is. Verder is daar ook die probleem dat alle bronne slegs weergawes van die oorspronklike 'feite' is. Alle weergawes is altyd persoonlik en subjektief en word boonop as narratief aangebied. ${ }^{7}$

Een of ander metode word altyd gevolg vir geskiedskrywing. Daar bestaan soveel verskillende metodes (elke metode is weer onderhewig aan druk ${ }^{8}$ ), maar daar bestaan geen grond waarvolgens voorkeur aan een metode bo 'n ander gegee kan word nie. Daarom wys Jenkins daarop dat die epistemologie sowel as die metodologie uiteindelik deur ideologie bepaal word. Konsensus ('n 'kanonieke' geskiedenis) ontstaan slegs wanneer een diskoers ander diskoerse domineer deur uitsluiting of koöptering. Geskiedenis is daarom, vir Jenkins", nooit "geskiedenis van ..." nie maar altyd "geskiedenis vir ...".

In plaas daarvan om die geskiedenis dus te beskou as ' $n$ vak (dissipline) wat op natuurlike en vanselfsprekende wyse bestaan en waarop naïewe en objektiewe reaksie moontlik is, word geskiedenis eerder beskou as 'n doelgerigte wyse waarop die verlede (deur persone met besondere belange daarby) georganiseer is - met 'n spesifieke doel.

In historiografiese metafiksie word die nosie dat geskiedenis objektiewe, neutrale feite is, voortdurend ondergrawe deur feit en fiksie te venneng, deur die klem op taal te plaas, deur apokriewe geskiedenis te skep, sogenaamde 'sameswerings' te ontdek en deur ontluistering. Deur die geskiedenis dan op ooglopende (dikwels selfbewuste) wyse aan te bied as deur die verteller gemanipuleer, word objektiewe reaksie onmoontlik gemaak. Geskiedskrywing word as diskoers (Foucault, 1972) blootgelê met die gevolg dat die leser se eie bewuste en onbewuste verwysingsraamwerk blootgelê word. In postmodernistiese fiksie is die teks altyd besig

7 Dic invloed van narraticwe in verskeic studicvelde word byvoorbecld deur Kreiswirth (1992) bespreck.

8 Jenkins (1991:19) noem in hicrdic verband dic druk van verskcic grocpc warin die wat mag het uitcindelik dic diskocrs bepaal: Geskicdenis is "a contested discourse, an embaltled terrain whercin people(s), classes and groups autobiographically construct interpretations of the past literally to please themselves. There is no definitive history outside these pressures, any (temporary) consensus only being reached when dominant voices can silenec others by overt power or covert incorporation".

9 "In the end history is theory and theory is ideological and idcology is just matcrial interests" (Jenkins, 1991:20) 
om homself binne sy diskursiewe raanwerk te plaas (deur selfrefleksie) en om sodoende opvattings oor kennis, hetsy histories, sosiaal of ideologies te bevraagteken.

Voorts word gewys op enkele spesifieke maniere waarop die nosie van geskiedenis as objektiewe feite in Het beleg van laken en Kroniek uit die doofpot ondergrawe word.

\subsection{Metafiksionaliteit: die vestiging van die aandag op skrywe as taal}

Belangrik in Hel beleg van Laken is die klem wat geplaas word op die probleem om beelde (geskiedenis) deur middel van taal weer te gee: "Vóór het schrijven was er al taal, maar vóór taal waren er beelden. Ik moet zover mogelijk teruggaan" (Laken:105). Walter van den Broeck (die karakter) probeer immers on die koning se vraag na die rede waarom hy skryf te beantwoord. Hy probeer die vraag beantwoord deur te skryf; deur ervarings sedert sy jeug op te teken. Skrywe (taal) is 'n poging om van "beeld-zijn" tot "ik-zijn" te kom (laken:180). Lewe hang uiteindelik af van skryf (Laken:211), wat ook bevestig word deur die verdwyning (moontlike dood) van Loracq sodra hy klaar geskryf het.

In Kroniek uit die doofpot besef die skrywer dat die lewe nooit in taal weergegee kan word nie. "Daardie lewe is net nog 'n woord, 'n doekie wat taal ons om die oë draai ..." (Kronick:16).

Die gebruik van taal, deur die vertel van verhale (natuurlik ook die vertel van geskiedenis) is 'n soeke na mag. Van den Broeck besef dit:

Helemaal deurgloed van machtswellust deed ik naar hartelust beelden verschijnen en verdwijnen. Alles kon! Zelfs dat wat niet kon! Wat een geilige weelde! (Laken:338).

Hierdie almag van die skrywer blyk ook in Kronick uit die doofpot. Die skrywer dink weer aan die koerantberig wat die hoofkarakter, Tumelo John, gelees het en dink daaraan dat liy dit kan verander na 'n berig oor Verwoerd (Kroniek:106).

In Het beleg van Laken word die aandag ook op taal gevestig deur die weergawe van byvoorbeeld die Kempense dialek: "Ik ondervind bijzonder veel plezier bij het rekonstrueren van het dialekt van de oude Mallants. Makkelijk is het echter niet ..." (Laken:152). Die hoogs subjektiewe weergawe van die koninklike geskiedenis, waardeur die 'klein mens' ook homself in die geskiedenis 'in-skryf' vind plaas in sy eie taal. Taal (die klein mens se variasie daarvan) gee hom mag oor die geskiedenis. Insgelyks is dit Vusi, die digter, wat die skrywer daarop wys dat hulle die geskiedenis skep - op die teerpad van Temba na Eersterus (Kronick:351). 
Die skrywer in Kroniek uit die doofpot skryf spesifiek in Afrikaans, ten spyte van die klagtes dat dit dan vertaal moet word vir die oorsese mark. Hy verduidelik aan die agterdogtige Rappuni dat hy in Afrikaans wil skryf sodat mense kan besef dat daar Afrikaners is wat anders dink (Kroniek:301). Die skryfhandeling is dus ook 'n proses om Afrikaanssprekendes te bemagtig.

Die hoofstukke waarin die storie van Tumelo Jolın vertel word, word telkens gevolg deur 'n kort kommentariënde hoofstuk deur die skrywer op die skryf van die storie. Die onmoontlikheid van die skryf van 'n objektiewe geskiedenis word hierdeur blootgelê. Alle gebeurtenise uit die verlede, hoe goed dit ook al gedokumenteer is, kan slegs vanuit die huidige verstaan word. ${ }^{10}$ Elke gebeurtenis word dan ook gesien in die lig van wat daarop gevolg het. Die skrywer se vriend verklaar byvoorbeeld Van Niekerk se optrede teen die agtergrond van die gebeurtenisse rondom September 1984: die herdenking van Steve Biko se dood en die nuwe grondwet wat voorsiening maak vir 'n president met uitvoerende magte, word in verband gebring met die aanranding van Tumelo John (Kronick:105). Die datums by elke hoofstuk - een datum uit die verlede telkens opgevolg deur ' $n$ ander datum uit die skrywer se hede - plaas verder klem op die teleologiese aspek van geskiedskrywing.

Gesprekke tussen die skrywer en sy uitgewer en die besprekings van afgehandelde hoofstukke en karakters betrek die leser by die ontstaansproses van hierdie talige teks (Kroniek:82-83). Juis ondat die gesprekke met 'n uitgewer gevoer word, word die leser herinner daaraan dat hierdie 'n roman is, geskryf om gepubliseer te word. 11

\section{2 'n Apokriewe geskiedenis word geskep}

Die koninklike familie word in $\mathrm{Het}$ beleg van Laken nie daarvan gespaar dat verskeie apokriewe gebeurtenisse aan hul toegedig word nie. Die troue van Leopold met Lilian sou, volgens Mallants, deur die pous self waargeneem word. Die pous lees egter later in die koerant (sic) van die onenigheid oor die troue en besluit dan om die troue liewer nie self waar te neem nie.

10 Een van dic epistemologiese probleme van historiografic waarop Jenkins (199I) wys, is dat geskicdenis altyd met 'n terugskouende perspekticf en insig geskryf word.

11 Metafiksionele kommentaar is nic beperk tot dic hoofstukke waarin dic skrywer sy skryfproses blootlê nic Ook 'in' dic storic van Tumelo John word dic leser telkens aan dic tekstualiteit, dic taligheid daarvan herinner deur: "Met sy trouc vroeg in 1977 Dis waar ons hom laas gelos het" (Kroniek:55), of "Natuurlik het Nkosi ouer geword sedert jy laas van hom gelecs het ..." (Kroniek.75). 
Die gevolg van die verdeling van die boeke van Leuven se biblioteek na die 1968-skeiding is dat al die dokters en advokate slegs die helfte van die kemnis het wat nodig is. Hierdie perspektief van Mallants, eie aan 'n naiewe gemoed, lê juis die subjektiwiteit van sy weergawe van die geskiedenis (en by implikasie elke weergawe van die geskiedenis) bloot.

Deur sulke apokriewe gebeurtenisse as 'feite' in die geskiedskrywing / vertelling (in die geval van Mallants) op te neem, word die 'raan' van fiksie verbreek (deur aan die verhaal die status van geskiedkundige feit te verleen), maar ook die 'raam' van die geskiedenis word verbreek (omdat fiksie daarin as 'feit' opgeneem word).

Opvallend in Het beleg van Laken is die ligte trant. Die spottende wyse waarop apokriewe geskiedenis geskep word is vennaaklik. Hierdie ligtheid ontbreek in Kronick uit die doofpot en in hierdie opsig is dit dan ook nie 'n kenmerkende postmodemistiese teks nie.

As toevoeging tot die amptelike diskoers van die maghebbers is die geskiedenis van Tumelo John 'n apokriewe geskiedenis. Die geskiedenis word geskep deur die mense waarvan die amptelike geskiedenis nie eens bewus is nie (Kronick: 351 ). Hierdie gemarginaliseerde geskiedenis word dus as apokriewe geskiedenis 'geskep' te midde van die gevaar van vervolging deur diegene wat die amptelike diskoers beheer (die skrywer besluit om alles as fiksie aan te bied - Kronick:52).

Die geskiedenis van Tumelo John is 'n petit histoire. Tumelo John is immers "'n naam wat wegraak in 'n see van ander name, 'n naam wat nie van naamloosheid te onderskei is nie" (Kronick:15). Hierdie geskiedenis word eenvoudig uit die maghebber se diskoers gesluit. Die gevolg van hierdie uitsluiting is juis dit wat die skrywer noop om die apokriewe storie van Tumelo John op te teken - 'n storie wat uitgesluit word uit die amptelik "geslote lêer". Die kanonieke geskiedenis veroorsaak "gelowiges sonder geheue" (Kronick:354).

\subsection{Ontdekking van sameswerings}

Die ontdekking van allerlei sameswerings in die verlede wat dan eintlik vir die verloop van die geskiedenis verantwoordelik son wees, word dikwels in postmodernistiese tekste aangetref. 12 Die oorsake van gebeure soos dit in die geskiedenis opgeneem is, word hierdeur afgemaak.

12 Dink byvoorbecld aan Pynchon se The Crying of Lot t9 (1979) cn Eco sc Foncault s Pendulum (1989) 
In Het beleg van Laken word sameswerings blootgelê waardeur die 'ware' oorsake van gebeure in die doofpot gesteek is. Loracq se geheimsinnige opdraggewers blyk lede van ' $n$ "geheim genootschap van radikale royalisten" te wees (Laken:383). Die enigste doel wat Loracq en sy opdraggewers voor oë het, is om "het grootste komplot uit de geschiedenis van de dynastie" bloot te lê (Laken: 385). Dit is dan ook hierdie 'geheime genootskap' wat poog om te keer dat kennis van die eintlike oorsaak van die verloop van die geskiedenis (naamlik die spanning tussen paleis en tuin; Rede en Romantiek; monargie en demokrasie; vergaar en skei) 'ontydig' bekend sou word (laken:388). Die spanning tussen paleis en tuin - Rede en Romantiek - word egter te sterk en daarom beweer Loracq byvoorbeeld dat die paleisbrand van 1890 in der waarheid ' $n$ selfmoordpoging van die Rede was.

Deur dergelike 'sameswerings bloot te lề' word aangedui op hoeveel aannames die erkende geskiedskrywing eintlik berus. Deur soveel moontlik vergesogte oorsake vir gebeurtenisse in die geskiedenis te gee, word die 'gesag' van die erkende geskiedskrywing, teen die agtergrond van hierdie ander moontlikhede, uiteindelik as slegs nóg 'n moontlikheid gesien. Die moontlikheid dat die sogenaamde 'amptelike' geskiedenis ook deur 'n sameswering bepaal is, word hierdeur geskep. Die feit dat enige vorm van geskiedskrywing wel ook diskoers is wat deur sekere reëls bepaal word ('n idee wat veral deur Foucault ook beredeneer word), word sodoende beklemtoon.

In Kroniek uit die doofpot word 'n 'sameswering' blootgelê wat dit duidelik maak dat die geskiedenis eintlik gemanipuleer word, bepaal word deur diegene wat die mag het. Die noue verbintenis tussen kennis en mag, soos Foucault in Power Knowledge (1981) uiteensit, word sodoende duidelik. Hierdie geskiedenis word vergeet. Daar is ' $n$ sameswering deur die polisiehoofde om die hele kroniek 'in die doofpot te steek' en 'n ander geskiedenis te laat oorleef as 'waarheid'. 'n Moordbende word gebruik om Tumelo John stil te maak. Die sameswering word verder moontlik gemaak deur die bure sodanig te intimideer dat niemand durf sê dat die polisie dit gedoen het nie. Die gewone mense word sodoende deel van die sameswering.

Uiteindelik is die skrywer natuurlik ook 'n 'samesweerder' wat sy weergawe van die geskiedenis voorhou. Die leser word weer op sy beurt by hierdie sameswering betrek wanneer hy die teks lees.

\subsection{Fantasie en geskiedenis word geīntegreer}

Die verhouding tussen fantasie en historiese 'feit' word in albei romans geproblematiseer. In die ontkenning voor in Het heleg van laken word die problematiese verhouding tussen feit en fiksie reeds onder die leser se aandag gebring: 
Doordat ze in dit boek voorkomen zijn alle èchte personen, plaatsen en gebeurtenissen net zo fiktief als de personen, plaatsen en gebeurtenissen die ik verzonnen heb (Laken:4)

Hierdie problematiek word verder versterk deur die wyse waarop die verteller geïdentifiseer word as Walter van den Broeck, die reèle outeur (Laken:18). Die teks wat as fiksie aangebied word ("een moorddroom"), maak hierdeur tog ook 'n 'waarheidsaanspraak', versterk deur die verwysings na vorige tekste uit Van den Broeck se oeuvre en literêre kritici.

Ook in Kronick van die doofpot is die vermenging van feit en fiksie nie eenvoudig nie. Die skrywer sê dat hy met die 'gegewe feite' gaan inmeng:

... dat my brousel so deurmekaar sal lyk soos die waarheid self. Daarom sal ek Tumelo John, Tumelo John noem om die verwardes te verwar en die verbeeldingrykes te laat sien (Kroniek:54).

In Het beleg van Laken is daar twee weergawes van die geskiedenis van die koningshuis van België. Dieselfde gegewe, die datums waarop konings sterf of aan bewind kom, met wie hulle trou en die geboorte (al dan nie) van hulle kinders, word deur Mallants en Loracq gebruik in hulle uiteenlopende weergawes van hierdie geskiedenis. Dit is dan ook juis uit die groot verskil tussen die twee weergawes van dieselfde geskiedenis dat dit blyk in welke mate geskiedeniskrywing eintlik ' $n$ integrering van fantasie en feite is. ${ }^{13}$

Met sy verklarende model (wat ooglopend fiksie is), is dit vir Loracq vanselfsprekend om gebeurtenisse uit die geskiedenis te verklaar. Die spanning tussen tuin en paleis bepaal die Oostenrykers se oomame en verdwyning (Laken:292); die Franse se oomame (Laken:292); Napoleon se uiteindelike ondergang te Waterloo, nadat hy die fatale Russiese veldtog juis in Schoonenberg beplan het (Laken:296); en Nederland se uiteindelike onttrekking aan België. Dit dien selfs as verklaring van die koning se kinderloosheid.

In Kronick uit die doofpot is die skrywer voortdurend selfbewus besig om die tekste tot sy beskikking (hofverslae en prokureursverslae ens.) met fantasie aan te vul ten einde 'n 'storie' uit die skraps 'feite' te kan mak. Die skrywer wat besig is om 'n roman van Tumelo John se lewe te maak, maak selfbewus van sy verbeelding gebruik: "Ek stel myself voor dat Tumelo John van tyd tot tyd aan sy

13 In dic ou man, Mallants, se weergawe van dic geskiedenis van dic koningshuis, word fantasic en geskicdenis deurgaans geintegreer Hy vertel byvoorbecld van dic jong prins Boudewijn wat gedroom het dat hy sy vulpen aan 'n Kempense scun gegec het. Later lees hy dan van hicrdic gebcurtenis in dic bock (Brief aan Boudewijn) van Walter van den Brocck (dic Kempense scun) Dic fantasic (dic fiksic van Van den Brocek - Brief aan Boudewijn) word dus onontwarbaar deel van dic 'geskiedenis' volgens Mallants 
oupa sou terugdink" (Kroniek:13). Hy het sekere feitelike gegewens tot sy beskikking uit die verslae en lêers. ${ }^{14}$ Hierdie gegewens word deur die skrywer in 'n reeks van oorsaak en gevolg geplaas. ${ }^{15}$ Die geskiedenis van Tumelo John word dan die storie van die skrywer (Kroniek:16). Die skrywer is doelbewus besig om die geskiedenis van Tumelo John weer te gee as fiksie - tot die skok van die prokureur wat hom van die saak bewus gemaak het (Kroniek:52).

Die skrywer besef hy sal moet verander aan baie aspekte:

Die besonderhede wat ek nie kan uitvind nie, sal ek uitdink; ander se menings sal ek met my eie aanvul en my onkunde moet ek verberg agter die seepgladheid van 'n storie (Kroniek:53).

Sy poging is nie om fantasie na willekeur die oorhand te gee nie, maar hy bly versigtig binne die 'duister kolle' van die beskikbare tekste - bloot as aanvulling tot die skraps dokumente sodat dit 'storie' kan wees. Boonop is die dokumente nie volledig nie - soos geen dokumentasie oor die verlede ooit so omvattend kan wees dat die ganse verlede daardeur weergegee kan word nie (een van die epistemologiese probleme met geskiedskrywing - Jenkins, 1991:11). In hierdie geval is dit duidelik dat die maghebbers - die skrywers van die 'ware' geskiedenis doelbewus sekere dokumentasie vernietig het:

Daar is soveel gapings in die hele geskiedenis, meer gapings as geskiedenis, byvoorbeeld hierdie verslag van 'n departementele ondersoek, dit begin op bladsy 11 , waar is die eerste tien? Lyk my selfs die dokumente is onvolledig (Kroniek:52).

\subsection{Ontluistering van luisterryke geskiedenis}

In Het beleg van Laken word die "oude glorie" van die dinastie gerelativeer deur beskrywings van die vroeëre konings. Enige luister wat aan Koning Leopold I verleen kon word, word ontdaan deur die wyse waarop sy tweede huwelik as 'n huwelik van die rede beskryf word. Leopold II word weer as "het meest beruchte fuifnummer van West-Europa" beskryf (Laken:299).

Daar is geen luister meer aan hierdie geskiedenis wat tegelyk treurig en komies is nie (Laken:310). Koning Boudewijn word uiteindelik beskou as die kurator, belas met die likwidasie van België:

14 Dic skrywer beskik byvoorbecld oor spesificke datums: "Op Vrydag 25 Mci 1973 begin Tumelo John Moleko sy diens by dic Suid-Afrikaanse Polisic in Cleveland Johannesburg" (Kroniek.14)

15 "Hy het die warboel verklarings, bricwe, 'n oncindige aantal vorms - wat 'n armsalige becld van 'n lewe - in 'n lyn van oorsaak en gevolg probecr plaas" (Kroniek. 16). 
Boudewijn zou er echter niet in slagen de dynastie in haar oude glorie te herstellen. Integendeel, het werd van jaar tot jaar duidelijker, dat hij in feite niet meer was dan een curator, die was belast met de likwidatie van de vennootschap België (Laken:309).

Deur die 'ontheiliging' van die geskiedenis word bevestig dat geskrewe geskiedenis 'n diskoers is wat deur sekere reëls bepaal word.

Die luisterryke geskiedenis van reg en geregtiglıeid, dat boosdoeners deur die polisie gevang word en die goeie mense beskenm word, word in Kronick uit die doofpot ontluister. Tumelo John sluit by die polisie aan juis omdat hy voel dat hy op daardie manier die Reg kan dien: "... as kind was dit al vir hom 'n eerbare beroep, om in diens van die Reg te wees, om goeie mense by te staan ..." (Kroniek:35). Dit is hierdie beeld van die polisie wat ook deur die misdaadverslaggewer voorgehou word. Hy beskryf die polisie as mense van integriteit (Kroniek:142). Selfs die veiligheidspolisie se integriteit mag nie in twyfel getrek word nie, omdat luulle, volgens die verslaggewer, nie by die politiek betrokke is nie maar vir die land se veiligheid werk (I.aken: 143).

Die beeld wat egter geleidelik uit die geskiedenis van Tumelo John ontstaan, verskil van hierdie weergawe. Die polisie is sloerders en toesmeerders: hulle laat die saak lank genoeg sloer sodat Tumelo John nie meer die prokureurskoste kan dra nie (Kroniek:241). Dan word interne ondersoeke gedoen - met voorspelbare gevolge; diegene wat die mag het, bepaal die waarheid en die geskiedenis. Die polisie manipuleer intern die geskiedenis deur lêers te laat wegraak wanneer die prokureur daarna vra (Kroniek:213).

Die geskiedenis word uit elke perspektief op 'n ander manier beskryf. Soos die skrywer dit verwoord: "'Wat die een groep sien as misdaad is die ander se lewe ... 'n misdadige lewe'" (Kroniek: 104).

\section{Viering vs. gebruik}

In albei tekste word ontologiese twyfel in historiografie gevestig. In Het beleg van Laken word dit gevier dat daar nie meer slegs 'n enkele perspektief toegelaat word nie. Hierdie verruimde visie gee die klein mens (soos die Kempense skrywer Van den Broeck/ Mallants/ Loracq) aanspraak op 'n ewe geldige waarheid.

Die ondergang van die Groot Metanarratief van die Rede word gevier: "skei en vergaar" bepaal alles, nie die oorsaak en gevolg van die Rede nie (I.aken:310). Loracq beweer selfs dat die paleisbrand van 1890 in der waarheid 'n selfmoordpoging van die Rede was (laken:317). 
Op gepaste wyse vind hierdie viering in ligte trant plaas, gekenmerk deur die speelsheid van postmodernistiese tekste. Daar is immers geen swaarmoedigheid in die beskrywing van Loracq wat, ten spyte van sy groot lyf, soos ' $n$ Boeddha op die kas sit en slaap nie. Al die 'inmengings' met die aanvaarde, gekanoniseerde geskiedenis hierbo bespreek, word op ligte, spottende wyse gedoen - dit is immers ' $n$ 'moorddroom'. Die effek is nie slegs een van destruksie nie; die leser word juis ook geamuseer.

Hierdie viering staan in skerp kontras met Kroniek uit die doofpot. Die ondergrawing van die sentrale diskoers word nie vrolik en lig gevier nie. Daar is nie ligtheid nie. Die twyfel aan sentralisering, die twyfel aan die meesternarratief, word met erns gebruik om 'n gemarginaliseerde geskiedenis te vestig. (Agter daardie een vuishou sit 'n geskiedenis van rassediskriminasie - Kroniek:174.)

Geskiedenis bestaan dikwels slegs uit grafieke en tabelle en dit gee nie werklik die hele geskiedenis weer nie. Die skrywer wil karakters skep - wat langer onthou sal word as enkele tabelle en statistiek (Kroniek:175). Oor tabelle en statistiek kan lesers nog afstandelik gesels. Karakters in 'n roman is egter meer as bloot statistiek. Die leser word betrek by die lewens van die karakters. Die lesers kan in die karakters iets van hulself herken (Kroniek:176). Hierdie selfherkenningsproses kan hopelik lei tot die voorkoming van 'n nuwe "onmisbare dwang" waarin gelowiges sonder geheue kan bieg: "... ons het nie geweet nie" (Kroniek:354). Hierin lê dan die gebruik van wantroue in meesterverhale. Deur te voorkom dat ' $n$ enkele meesterverhaal aanvaar word, die sentrum inneem, kan voorkom word dat 'n "onmisbare dwang" ontstaan.

\section{Gevolgtrekking}

Dit sou pretensieus wees om, na aanleiding van 'n bespreking van slegs hierdie twee tekste, te beweer dat Europese tekste meer geneig is om die ondergrawing van meesterverhale vrolik te vier, terwyl Afrika-tekste eerder hierdie ondergrawing doelgerig, met erns aanwend om sekere meesterverhale (soos apartheid) te ondergrawe. Daar kan wel ten minste afgelei word dat daar in sommige historiografiese metafiksie 'n meer doelgerigte, ernstige ondergrawing van sentrums is terwyl ander tekste ' $n$ speelse viering van die verval van die meesterverhale openbaar. Dit is moontlik waar dat sulke vrolikheid 'n luukse is wat tuishoort in 'n laat-kapitalistiese Westerse kultuur, en daarom onvanpas is in 'n ontwikkelende land. Hier is nie plek vir moorddrome nie, hier is dit moord. 


\section{Bibliografie}

Bousset, H. 1990. Grenzen verleggen. De Llaamse prozaliteratumr 1970-1986. II Profielen Antwerpen : Houtekiet.

Eco, U. 1989. Foucault's Pendulum. London: Secker \& Warburg.

Foucault, M. 1972. The Archaeology of Knowledge. New York : Pantheon.

Foucault, M. 1981. Power/Knowledge. New York: Pantheon

Hutcheon, L 1989. A Poetics of Postmodermism. London \& New York : Routledge

Jenkins, K. 1991. Rethinking History. London : Routledge.

Kreiswirth, M. 1992. Trusting the Tale: The Narrativist Turn in the Human Sciences. New' Literary History, 23(3):629-657.

Lyotard, J. 1984(1979). The Postmodern Condition: A Report on Knowledge Vertaal uit Frans deur Geoff Bennington en Brian Massumi. Manchester : Manchester University Press

Mchale, B 1987. Postmodernist Fiction. London : Routledge

Miles, J. 1991. Kromiek wit die doofpot. Bramley: Taurus.

Pynchon, T. 1979. The Crying of Lot 19. London : Picador.

Sloterdijk, P. 1992 Kritiek van de cynische rede Amsterdam : Arbeiderspers.

Van den Broeck, W. 1985. Het beleg van Laken. Antwerpen : Manteau

\section{Universiteit van Zoelocland}


